\title{
Daily Medication Management and Adherence in the Polymedicated Elderly: A Cross-Sectional Study in Portugal
}

\author{
Daniel Gomes ${ }^{1,2}$, Ana Isabel Placido ${ }^{1}$, Rita Mó ${ }^{3}$, João Lindo Simões ${ }^{4}$, Odete Amaral ${ }^{5}$ (D, \\ Isabel Fernandes ${ }^{1}$, Fátima Lima ${ }^{6}$, Manuel Morgado 1,3,7,8 $\mathbb{D}$, Adolfo Figueiras 9,10, \\ Maria Teresa Herdeiro ${ }^{11}$ and Fátima Roque ${ }^{1,8, *(D)}$ \\ 1 Research Unit for Inland Development-Polytechnic of Guarda (UDI-IPG), 6300 Guarda, Portugal; \\ danielsgomes98@hotmail.com (D.G.); anaplacido@ipg.pt (A.I.P.); isabelfernandes@ipg.pt (I.F.); \\ mmorgado@ipg.pt (M.M.) \\ Centre for Health Studies and Research of the University of Coimbra, 3000 Coimbra, Portugal \\ Health Sciences Faculty, University of Beira Interior (FCS-UBI), 6200 Covilhã, Portugal; \\ ritamdmo@hotmail.com \\ 4 Center for Health Technology and Services Research (CINTESIS), 4000 Porto, Portugal; jflindo@ua.pt \\ 5 Health Sciences School, Polytechnic of Viseu IPV, 3430 Viseu, Portugal; mopamaral@gmail.com \\ 6 Local Health Unit of Guarda (ULS Guarda), 6300 Guarda, Portugal; \\ dir.csaudeprimarios@ulsguarda.min-saude.pt \\ 7 Pharmaceutical Services, University Hospital Center of Cova da Beira (CHUCB), 6200 Covilhã, Portugal \\ 8 Health Sciences Research Centre, University of Beira Interior (CICS-UBI), 6200 Covilhã, Portugal \\ 9 Department of Preventive Medicine, University of Santiago de Compostela, 15702 Santiago de Compostela, \\ Spain; adolfo.figueiras@usc.es \\ 10 Centro de Investigación Biomédica en Red de Epidemiología y Salud Pública (CIBER-ESP), \\ 28001 Madrid, Spain \\ 11 Department of Medical Sciences and Institute of Biomedicine, University of Aveiro (iBIMED-UA), \\ 3800 Aveiro, Portugal; teresaherdeiro@ua.pt \\ * Correspondence: froque@ipg.pt; Tel.: +351-271-205-220
}

Received: 6 December 2019; Accepted: 23 December 2019; Published: 27 December 2019

\begin{abstract}
The presence of age-related comorbidities prone elderly patients to the phenomenon of polypharmacy and consequently to a higher risk of nonadherence. Thus, this paper aims to characterize the medication consumption profile and explore the relationship of beliefs and daily medication management on medication adherence by home-dwelling polymedicated elderly people. A questionnaire on adherence, managing, and beliefs of medicines was applied to polymedicated patients with $\geq 65$ years old, in primary care centers of the central region of Portugal. Of the 1089 participants, $47.7 \%$ were considered nonadherent. Forgetfulness (38.8\%), difficulties in managing medication $(14.3 \%)$, concerns with side effects $(10.7 \%)$, and the price of medication $(9.2 \%)$ were pointed as relevant medication nonadherence-related factors. It was observed that patients who had difficulties managing medicines, common forgetfulness, concerns with side effects, doubting the need for the medication, considered prices expensive, and had a lack of trust for some medicines had a higher risk of being nonadherent. This study provides relevant information concerning the daily routine and management of medicines that can be useful to the development of educational strategies to promote health literacy and improve medication adherence in polymedicated home-dwelling elderly.
\end{abstract}

Keywords: elderly; polypharmacy; daily management of medication; medication adherence; self-care; nonadherence related factors 


\section{Introduction}

According to the United Nations (UN), the number of elderly ( $\geq 65$ years) will double until 2050 [1]. One of the reasons explaining the worldwide ageing of population is the exponential technological contributions in the medicine and public health field, leading to an increase in life expectancy and decrease of mortality rate [2,3]. Medicines are the medical technology mostly used and, according to literature, the concomitant use of five or more medicines, the most widely accepted definition of polypharmacy, affects $40-50 \%$ of elderly in high-income countries [4-7]. The use of multiple medication contributes to an incorrect use of medicines by the elderly and may potentially increase the risk for a Drug Related Problems (DRPs) occurrence, therefore interfering with the treatment effectiveness and safety [8-10]. In this context, DRPs in the elderly account for a large percentage of emergency treatment and hospitalizations, increasing the costs with health in the most aged regions [11-13]. In addition, levels of adherence to drug therapy correlate inversely with the number of drugs prescribed, especially in the elderly who do not live in nursing homes [8,14].

Adherence in the elderly can be compromised, either by volunteering interrupt or modify the therapy, by mistakenly believing that they are properly adhering, or ascribed to some relevant socio-economic factors, elder's perceptions, motivations and physical and cognitive impairment, their own condition, and even the complexity of the therapy [14-16].

Since Portugal is one of the most aged countries in the world and the center region of Portugal is the second region with the highest aging index in the country $[17,18]$, we designed the MedElderly project, which the main goal is the identification of DRPs in the older patients and the development of an intervention to improve medication use by this population. In this paper, we present the results of the first phase of the project that aim to characterize the medication profile consumption, assess medication adherence, and identify relevant risk factors affecting adherence in home-dwelling older patients of the center region of Portugal.

\section{Materials and Methods}

\subsection{Setting, Study Population, and Sample Selection}

A cross-sectional study was conducted in 38 public primary care centers between April and August 2019, belonging NUTS II (Nomenclatura das Unidades Territoriais para Fins Estatísticos/Nomenclature of Territorial Units for Statistics) area of Portugal defined by the Center Regional Health Administration (Administração Regional de Saúde do Centro/ARS-C). Primary care health centers of ARS-C are organized in nine clusters. The study took place in five clusters with 227,785 elderly patients registered. The target population included home-dwelling patients 65 years or older taking five or more medicines. Individuals with cognitive impairment or mental conditions that prevented them from responding appropriately and those who lived in nursing homes were excluded from the study. The sample population of the study was calculated based on the number of elderly patients that are registered in primary care centers and an estimated prevalence of elderly with medication misadventures of $30 \%$ keeping a $95 \%$ confidence level and a $5 \%$ tolerated error level. Considering a possible refusal rate of $20 \%$, the final sample size was calculated to be 387 older patients.

\subsection{Questionnaire Design}

To assess medication adherence and risk factors of medication misadventures in a target population, a questionnaire was designed taking into account data from two qualitative studies with focus-group sessions held with older patients [17] and healthcare professionals (physicians, community pharmacists, and nurses) [18].

To ensure that the questionnaire was easily understood, well-defined, and accurately addressed the goals of the study, one clinical psychology expert, one general practitioner, two pharmacists, two nurses, and one Portuguese language expert evaluated face-validity parameters, such as the accuracy, the grammar, syntax, organization, appropriateness and logical sequence of the statements, and completeness and meaning of items. Moreover, to clarify possible problems of comprehension 
with any questionnaire item, a pre-test was conducted, eleven older adults were invited to complete the questionnaire and comment on any difficulties experienced in interpreting the respective items [19].

\subsection{Data Collection}

Healthcare professionals screened potential candidates for participation in each health care center, nursing and pharmacy students from four-health science institutions, approached potential participants before or after the scheduled visit to the doctor's appointment, for questionnaire application, confirmed their eligibility, and invited them to participate in the study. Participation in the study was voluntary, and all subjects received a detailed explanation about the goals, objectives, methods, and the purpose of the study. An application manual of the questionnaire and a training course were developed for the students who would apply it.

The structured questionnaire was 5 sheets long, 7 pages, divided in seven sections: Section 1 , containing information about the study, and instructions on how to complete the form and a box with information about the interviewers. The second section comprises multiple choice questions about daily administration of medications by patients, and the third section comprises affirmations about the elder's opinion about medicines, asking which ones he/she agreed with (yes or no question). The therapeutic adherence was evaluated in the fourth section with the "Medida de Adesão aos Tratamentos" (MAT) scale, by Delgado et al. [20], validated for the Portuguese population. This instrument consists of 7-items rated on a six-point Likert scale ranging from "Always" to "Never", and in all questions "Always" is the lowest adherence point and "Never" is the highest. The fifth section consists of 10-item scales rated on a four-point Likert scale (plus No answer) concerning situations that may sometimes contribute to not taking the medication exactly as prescribed, ranging from "Never happens" to "Happens almost every time". The sixth section concerns the sociodemographic characteristics of the participants and the last section intends to list all the chronic medication, extracted from the electronic records, then converted to the corresponding Anatomical Therapeutic Classification (ATC) code, using the WHO Collaborating Centre for Drug Statistics Methodology's web site [21].

\subsection{Statistical Analysis}

Data analysis was executed using the Statistical Package for Social Sciences (SPSS 25, IBM Corp., New York, NY, USA) and all $p$ values $\leq 0.05$ were considered statistically significant. Numerical and ordinal data were analyzed using descriptive statistics and presented in frequency and percentage and using mean, median, and standard deviation. The "Don't know/don't answer" situation was addressed and as considered missed values.

To measure the internal consistency of the applied scale, Cronbach's $\alpha$ was used. Cronbach's $\alpha$ can range from 0.0 to 1.0, and it quantifies the degree to which items on an instrument are correlated with one another.

Regarding the MAT scale, the adherence level from each individual was obtained summing up the values from the seven questions and dividing the value by the number of questions. The classification as adherent and nonadherent used the median as the cut value. Below the median, the sample is nonadherent and, above it, is adherent. To clear the results, whenever the adherence classification was involved, the sample within the median value was excluded [20].

The variables showed not to be normal $(p<0.001)$ so, for searching associations, non-parametric tests were used. For quantifying associations between two variables, continuous or ordinal, the Spearman Correlation value was obtained. For searching for risk factors interfering with adherence classification, multiple regression analyses were performed.

\subsection{Ethics Statement}

The project had the ethical approval of the Centre's Regional Health Administration (registry no. 105/2017) and the authorization of the healthcare centers directors. The participants granted informed consent prior to the administration of the questionnaire. The participants were codified and remained anonymous in the database. 


\section{Results}

\subsection{Sample Characterization}

Table 1 presents the sociodemographic characteristics of the sample. The mean $( \pm$ SD) age of the 1089 participants was $76.2( \pm 7.07)$, and $62.6 \%$ were women. In addition, $60.8 \%$ of the participants lived with a partner, $27.3 \%$ lived alone, and $8.6 \%$ with sons and/or grandchildren. Moreover, $76.5 \%$ of the participants had an education level of elementary school or higher, $7.7 \%$ did not know how to read or write, and $15.8 \%$ did know but without any degree. In addition, $58.8 \%$ of the participants had a monthly income less than 439 EUR. The mean of medication prescription was $6.82 \pm 2.03$, with a median of six medicines, and ranged from $5(n=348)$ to $17(n=1)$.

Table 1. Socio-demographic characteristics of the participants.

\begin{tabular}{|c|c|}
\hline$N=1089$ & $\%(N)$ \\
\hline \multicolumn{2}{|l|}{ Sex } \\
\hline Female & $62.6 \%(680)$ \\
\hline Male & $37.4 \%(407)$ \\
\hline \multicolumn{2}{|l|}{ Age } \\
\hline$(65-68)$ & $11.2 \%(121)$ \\
\hline$(68-71)$ & $15.1 \%(163)$ \\
\hline$(71-74)$ & $13.1 \%(141)$ \\
\hline$(74-77)$ & $15.8 \%(170)$ \\
\hline$(77-80)$ & $11.8 \%(127)$ \\
\hline$(80-83)$ & $12.0 \%(130)$ \\
\hline$(83-86)$ & $10.4 \%(112)$ \\
\hline$(86-89)$ & $6.0 \%(65)$ \\
\hline$(89-92)$ & $2.9 \%(31)$ \\
\hline$(92-95)$ & $1.1 \%(12)$ \\
\hline (95-99) & $0.6 \%(7)$ \\
\hline \multicolumn{2}{|l|}{ Monthly Income } \\
\hline$<439$ EUR & $58.8 \%(579)$ \\
\hline 440-580 EUR & $23.6 \%(232)$ \\
\hline 581-1160 EUR & $14.7 \%(145)$ \\
\hline$\geq 1161$ EUR & $2.9 \%(29)$ \\
\hline \multicolumn{2}{|l|}{ With Who Do You Live? } \\
\hline Alone & $27.0 \%(294)$ \\
\hline Partner & $60.1 \%(654)$ \\
\hline Son and/or Grandchildren & $8.5 \%(93)$ \\
\hline Others & $3.3 \%(35)$ \\
\hline \multicolumn{2}{|l|}{ Level of Education } \\
\hline Does not read or write & $7.7 \%(83)$ \\
\hline Knows how to read/write but no grade & $15.8 \%(171)$ \\
\hline Primary School & $57.7 \%(626)$ \\
\hline $2^{\circ}$ Cycle (5th and 6 th grade) & $7.0 \%(76)$ \\
\hline $3^{\circ}$ Cycle (7th to 9 th) & $4.8 \%(52)$ \\
\hline High School (10th to 12th) & $3.5 \%(38)$ \\
\hline Medium grade & $0.8 \%(9)$ \\
\hline Higher Education/Graduate & $2.7 \%(29)$ \\
\hline \multicolumn{2}{|l|}{ Region Living } \\
\hline Interior & $70.5 \%(768)$ \\
\hline Coast & $29.5 \%(321)$ \\
\hline
\end{tabular}

\subsection{Medication Consumption Profile}

Within anatomical groups of the ATC, the group A "Alimentary tract and metabolism" (1.32 \pm 1.07; min. 0; max. 6), group C “Cardiovascular system" (2.50 \pm 1.40 ; min. 0; max. 10), and group $\mathrm{N}$ 
"Nervous system" (1.32 \pm 1.29 ; min. 0; max. 8) were most frequent. Table 2 presents the frequency of individuals of the sample consuming medicines from the pharmacological Groups A, C, and N of ATC.

Table 2. Consumption of medicines from the fourth level pharmacological groups of Group A, Group C, and Group N.

\begin{tabular}{|c|c|}
\hline & $\%(N)$ \\
\hline \multicolumn{2}{|l|}{ Group A } \\
\hline A01A stomatological preparations & $0.2 \%(2)$ \\
\hline A02A antacids & $0.3 \%(3)$ \\
\hline A02B drugs for peptic ulcer and gastro-oesophageal reflux disease & $46.4 \%(501)$ \\
\hline A03A drugs for functional gastrointestinal disorders & $1.2 \%(13)$ \\
\hline A03B belladonna and derivatives, plain & $0.3 \%(3)$ \\
\hline A03F propulsives & $2.1 \%(23)$ \\
\hline A05A bile therapy & $0.1 \%(1)$ \\
\hline A06A drugs for constipation & $1.3 \%(14)$ \\
\hline A07A intestinal antiinfectives & $0.1 \%(1)$ \\
\hline A07D antipropulsives & $0.3 \%(3)$ \\
\hline A07E intestinal antiinflammatory agents & $0.7 \%(8)$ \\
\hline A07F antidiarrheal microorganisms & $0.2 \%(2)$ \\
\hline A09A digestives, incl. Enzymes & $0.4 \%(4)$ \\
\hline A10A insulins and analogues & $7.6 \%(83)$ \\
\hline A10B blood glucose lowering drugs, excl. Insulins & $37.3 \%(403)$ \\
\hline A11A multivitamins, combinations & $0.1 \%(1)$ \\
\hline A11C vitamin a and $d$, incl. Combinations of the two & $4.8 \%(52)$ \\
\hline A11D vitamin b1, plain and in combination with vitamin b6 and b12 & $1.7 \%(18)$ \\
\hline A11E vitamin b-complex, incl. Combinations & $0.3 \%(3)$ \\
\hline A11G ascorbic acid (vitamin c), incl. Combinations & $0.1 \%(1)$ \\
\hline A12A calcium & $6.4 \%(69)$ \\
\hline A12C other mineral supplements & $1.6 \%(17)$ \\
\hline A13A tonics & $0.1 \%(1)$ \\
\hline \multicolumn{2}{|l|}{ Group C } \\
\hline C01A cardiac glycosides & $2.3 \%(25)$ \\
\hline C01B antiarrhythmics, class i and iii & $3.9 \%(42)$ \\
\hline C01D vasodilators used in cardiac diseases & $4.9 \%(53)$ \\
\hline C01E other cardiac preparations & $5.8 \%(62)$ \\
\hline C02A antiadrenergic agents, centrally acting & $1.9 \%(20)$ \\
\hline $\mathrm{C} 02 \mathrm{C}$ antiadrenergic agents, peripherally acting & $0.2 \%(2)$ \\
\hline C03A low-ceiling diuretics, thiazides & $0.2 \%(2)$ \\
\hline C03B low-ceiling diuretics, excl. Thiazides & $9.2 \%(99)$ \\
\hline C03C high-ceiling diuretics & $18.7 \%(201)$ \\
\hline C03D potassium-sparing agents & $3.2 \%(35)$ \\
\hline C03E diuretics and potassium-sparing agents in combination & $1.6 \%(17)$ \\
\hline C04A peripheral vasodilators & $3.2 \%(35)$ \\
\hline C05A agents for treatment of hemorrhoids and anal fissures for topical use & $0.2 \%(2)$ \\
\hline C05B antivaricose therapy & $0.6 \%(6)$ \\
\hline C05C capillary stabilizing agents & $7.2 \%(77)$ \\
\hline C07A beta blocking agents & $26.7 \%(289)$ \\
\hline C07B beta blocking agents and thiazides & $0.2 \%(2)$ \\
\hline C07C beta blocking agents and other diuretics & $0.1 \%(1)$ \\
\hline C08C selective calcium channel blockers with mainly vascular effects & $14.8 \%(159)$ \\
\hline C08D selective calcium channel blockers with direct cardiac effects & $1.9 \%(20)$ \\
\hline C08G calcium channel blockers and diuretics & $0.1 \%(1)$ \\
\hline C09A angiotensin-converting-enzyme inhibitors, plain & $16.4 \%(176)$ \\
\hline C09B angiotensin-converting-enzyme inhibitors, combinations & $14.5 \%(156)$ \\
\hline C09C angiotensin II receptor blockers, plain & $18.3 \%(198)$ \\
\hline C09D angiotensin II receptor blockers, combinations & $21.3 \%(230)$ \\
\hline C09X other agents acting on the renin-angiotensin system & $0.2 \%(2)$ \\
\hline C10A lipid modifying agents, plain & $59.7 \%(644)$ \\
\hline C10B lipid modifying agents, combinations & $3.5 \%(38)$ \\
\hline
\end{tabular}


Table 2. Cont.

\begin{tabular}{lc}
\hline & $\%(N)$ \\
\hline Group N & \\
N01A anesthetics, general & $0.2 \%(2)$ \\
N02A opioids & $8.2 \%(88)$ \\
N02B other analgesics and antipyretics & $13.2 \%(143)$ \\
N02C antimigraine preparations & $0.1 \%(1)$ \\
N03A antiepileptics & $9.3 \%(100)$ \\
N04B dopaminergic agents & $2.9 \%(31)$ \\
N05A antipsychotics & $4.5 \%(48)$ \\
N05B anxiolytics & $38.6 \%(406)$ \\
N05C hypnotics and sedatives & $4.6 \%(50)$ \\
N06A antidepressants & $22.4 \%(242)$ \\
N06B psychostimulants, agents used for adhd and nootropics & $2.6 \%(28)$ \\
N06D anti-dementia drugs & $4.3 \%(46)$ \\
N07A parasympathomimetics & $0.1 \%(1)$ \\
N07C antivertigo preparations & $8.1 \%(87)$ \\
N07X other nervous system drugs & $0.1 \%(1)$ \\
\hline
\end{tabular}

Drugs for peptic ulcer and gastro-oesophageal reflux disease (46.4\%), blood glucose lowering drugs, excl. Insulins (37.3\%), beta blocking agents (26.7\%), lipid modifying agents (59.7\%), anxiolytics $(38.6 \%)$, and antidepressants $(22.4 \%)$ were highlighted as the most frequent.

\subsection{Medication Adherence Analysis}

According to Cronbach's $\alpha$, the MAT scale showed a satisfactory intern consistency ( $\alpha=0.767)$. The mean value of adherence level was $5.47 \pm 0.47$, and the minimum and maximum values obtained were 3 and 6 , respectively (Table 3). In addition, $47.7 \%$ of the sample had an adherence value below the median and were categorized as nonadherent.

Table 3. Minimum, maximum, mean and median of the adherence levels.

\begin{tabular}{ccccc}
\hline & Minimum & Maximum & Mean \pm SD & Median \\
\hline Adherence Level & $300(N=2 ; 0.2 \%)$ & $6.00(N=167 ; 15.4 \%)$ & $5.47 \pm 0.47$ & 5.57 \\
\hline
\end{tabular}

The single-question analysis of MAT scale revealed that (Table 4): the compliance with the medication schedule (second question) had the lowest mean $(4.99 \pm 0.82)$, and the fifth question, about taking one or more pills for the illness on their own after feeling worse had the highest mean (5.8 \pm 0.54$)$. Except for "Have you ever forgotten to take the medicines for your illness?" and "Have you ever been careless about the time you take your medicines?", the majority of answers was in the "Never", Likert scale point, ranged from $71.1 \%$ to $86.0 \%$ in the sixth question, regarding therapy interruption due to running out of medicines, and the fifth, regarding if the elderly takes more medicines when he/she feels worst, respectively. The medians from the third to the seventh questions had the maximum value possible (6.0). The frequencies were low in the three worst grades of the Likert scale, the highest $3.1 \%$ in the answer being "Often" in the first and second question. 
Table 4. Results from the Questions of Adherence Treatment Measure (MAT) and respective Mean and Median.

\begin{tabular}{|c|c|c|c|c|c|c|c|c|}
\hline & Always \% $(N)$ & Almost Always \% (N) & Often $\%(N)$ & Sometimes \% $(N)$ & Seldom \% $(N)$ & Never \% $(N)$ & Mean \pm SD & Median \\
\hline $\begin{array}{l}\text { 1. Have you ever forgotten to take } \\
\text { the medicines for your illness? }\end{array}$ & $0.1 \%(1)$ & $0.4 \%(4)$ & $3.1 \%(34)$ & $20.1 \%(219)$ & $45.4 \%(494)$ & $30.9 \%(336)$ & $5.03 \pm 0.83$ & 5 \\
\hline $\begin{array}{l}\text { 2. Have you ever been careless } \\
\text { about the time you take your } \\
\text { medicines? }\end{array}$ & $0.0 \%(0)$ & $0.7 \%(8)$ & $3.1 \%(34)$ & $20.7 \%(225)$ & $47.8 \%(521)$ & $27.6 \%(301)$ & $4.99 \pm 0.82$ & 5 \\
\hline $\begin{array}{l}\text { 3. Have you ever stopped taking } \\
\text { medicines for your illness because } \\
\text { you felt better? }\end{array}$ & $0.0 \%(0)$ & $0.2 \%(2)$ & $1.7 \%(19)$ & $8.2 \%(89)$ & $11.8 \%(128)$ & $78.1 \%(850)$ & $5.66 \pm 0.72$ & 6 \\
\hline $\begin{array}{l}\text { 4. Have you ever stopped taking } \\
\text { the medicines for your illness on } \\
\text { your own after feeling worse? }\end{array}$ & $0.1 \%(1)$ & $0.3 \%$ & $1.6 \%(17)$ & $10.2 \%(111)$ & $12.9 \%(140)$ & $75.0 \%(814)$ & $5.60 \pm 0.77$ & 6 \\
\hline $\begin{array}{l}\text { 5. Have you ever taken one or } \\
\text { more pills for your illness on your } \\
\text { own after feeling worse? }\end{array}$ & $0.0 \%(0)$ & $0.1 \%(1)$ & $0.8 \%(9)$ & $3.8 \%(41)$ & $9.3 \%(101)$ & $86.0 \%(937)$ & $5.80 \pm 0.54$ & 6 \\
\hline $\begin{array}{l}\text { 6. Have you ever interrupted } \\
\text { therapy for your illness because } \\
\text { you have run out of medicines? }\end{array}$ & $0.0 \%(0)$ & $0.2 \%(2)$ & $1.0 \%(11)$ & $8.9 \%(97)$ & $18.8 \%(205)$ & $71.1 \%(774)$ & $5.60 \pm 0.71$ & 6 \\
\hline $\begin{array}{l}\text { 7. Have you ever stopped taking } \\
\text { your medicines for some reason } \\
\text { other than doctor's appointment? }\end{array}$ & $0.0 \%(0)$ & $0.2 \%(2)$ & $0.9 \%(10)$ & $9.9 \%(108)$ & $12.6 \%(137)$ & $76.4 \%(832)$ & $5.64 \pm 0.7$ & 6 \\
\hline
\end{tabular}




\subsection{Medication Nonadherence Related Factors}

The most frequented medication nonadherence related factors pointed out by the elderly were the forgetfulness (38.8\%), difficulties in managing medication (14.3\%), concerns with side effects $(10.7 \%)$, and the price of medication $(9.2 \%)$ showed in Table 5.

Table 5. Frequencies on the reasons to not take the medication as prescribed.

\begin{tabular}{lc}
\hline $\begin{array}{l}\text { Sometimes You Do Not Take Your Medication } \\
\text { Exactly as Your Doctor Has Prescribed Because: }\end{array}$ & $\mathbf{\%}(\mathrm{N})$ \\
\hline a. Has difficulty managing so many medicines. & $14.3 \%(156)$ \\
b. Forgetfulness. & $38.8 \%(423)$ \\
c. Do not register as taking instructions. & $4.4 \%(48)$ \\
d. Concern with side effects. & $10.7 \%(116)$ \\
e. Hard to take. & $4.8 \%(52)$ \\
f. Doubt the need for the medication & $2.9 \%(32)$ \\
g. Price of medicines & $9.2 \%(100)$ \\
h. Not wanting to take medication and drink alcohol & $2.2 \%(24)$ \\
i. Not liking to take medications & $4.1 \%(45)$ \\
j. Do not trust some medications & $2.1 \%(23)$ \\
k. Interfere with social life & $3.3 \%(36)$ \\
\hline
\end{tabular}

Tables 6 and 7 presented a multiple regression analyses to identify factors associated with medication adherence in the participants. They revealed a positive correlation between the adherence levels and age and the number of medicines prescribed (Table 6).

Table 6. Spearman correlation between adherence level and age and medicines prescribed.

\begin{tabular}{cccc}
\hline & & Coefficient Value & Significance $(\boldsymbol{p}$ Value $)$ \\
\hline \multirow{2}{*}{ Adherence Levels } & Age & 0.077 & 0.018 \\
& Medicines Prescribed & 0.082 & 0.031 \\
\hline
\end{tabular}

Table 7. Factors influencing medication nonadherence.

\begin{tabular}{|c|c|c|}
\hline Independent Dichotomous Variables & OR $[95 \% \mathrm{CI}] *$ & $\mathrm{X}^{2}(p$-Value $)$ \\
\hline \multicolumn{3}{|l|}{$\begin{array}{l}\text { Sometimes you do not take your medication exactly } \\
\text { as your doctor has prescribed because: }\end{array}$} \\
\hline Has difficulty managing so many medicines & 1.720 [95\% CI 1.189-2.489] & 0.004 \\
\hline Forgetfulness & $3.370[95 \%$ CI $2.572-4.400]$ & $<0.001$ \\
\hline Do not register as taking instructions & $1.552[95 \%$ CI $0.835-2.885]$ & 0.161 \\
\hline Concern with side effects & $3.555[95 \%$ CI $2.248-5.626]$ & $<0.001$ \\
\hline Hard to take & $1.717[95 \%$ CI $0.919-3.208]$ & 0.087 \\
\hline Doubt the need for the medication & 3.910 [95\% CI 1.668-9.165] & 0.001 \\
\hline Price of medicines expensive & $2.290[95 \%$ CI $1.455-3.605]$ & $<0.001$ \\
\hline Not wanting to take medication and drink alcohol & $0.379[95 \%$ CI $0.148-0.969]$ & 0.036 \\
\hline Not liking to take medications & 0.815 [95\% CI 0.430-1.522] & 0.520 \\
\hline Do not trust some medications & $5.090[95 \%$ CI $1.711-15.163]$ & 0.001 \\
\hline Interfere with social life & $1.328[95 \%$ CI $0.661-2.667]$ & 0.424 \\
\hline \multicolumn{3}{|l|}{ Sociodemographic characteristics } \\
\hline Female & 1.408 [95\% CI 1.082-1.833] & 0.011 \\
\hline Male & $0.710[95 \%$ CI $0.546-0.924]$ & 0.011 \\
\hline Living alone & 1.187 [95\% CI 0.892-1.579] & 0.241 \\
\hline Not having level of education & $1.196[95 \%$ CI $0.889-1.608]$ & 0.237 \\
\hline Living in the Interior Region of Centre Portugal & $2.506[95 \%$ CI $1.874-3.351]$ & $<0.001$ \\
\hline Earning <439 EUR & $1.701[95 \%$ CI $1.314-2.203]$ & $<0.001$ \\
\hline
\end{tabular}

*CI-Confidence Interval. 
Moreover, the values of Odd ratio (Table 7) revealed that patients who had: (a) difficulties managing medicines (OR = 1.720, confidence interval 95\%, CL 1.189-2.489); (b) forgetfulness (OR = 3.370 , confidence interval 95\%,CI 2.572-4.400); (c) concerns with side effects, (OR $=3.555$, confidence interval 95\%, CI 2.248-5.626); (d) doubt the need for the medication (OR $=3.910$, confidence interval 95\%, CI 1.668-9.165); (e) prices expensive (OR = 2.290, confidence interval 95\%, CI 1.455-3.605); and (f) lack of trust for some medicines (OR $=5.090$, confidence interval 95\%, CI 1.711-15.163) had a higher risk of being non-adherent. Elderly with a monthly income less than $439 \mathrm{EUR}$ (OR $=1.701$, confidence interval 95\%, CI 1.314-2.203) had an increased probability of being non-adherent.

\subsection{Daily Medication Management}

Despite $82.7 \%$ of the participants being responsible for the managing of their medicine, $74.6 \%$ of the participants admitted that did not know the name of their medicines and recognized them only by: (a) the box $(56.7 \%)$, (b) the color of the pills $(12.8 \%)$, or (c) the shape of the pills $(5.1 \%)$. The participants admitted that, in the morning (fasting, $9.3 \%$ and breakfast, $10.4 \%$ ) and lunch $(10.7 \%)$ sometimes, they had difficulty in remembering to take their medicines. To avoid forgetfulness, the majority of the participants used a medication box (39.5\%), put the pills in different bags/places according to the schedule that the medicines must be taken $(23.3 \%)$ and at the beginning of the meal put the medicines on the table (20.8\%). Participants admitted that, in daily life, they had difficulties with schedules $(14.6 \%)$, swallowing the pills $(13.6 \%)$, remembering how they should take its medicines $(4.8 \%)$, and $2.1 \%$ affirmed that they had difficulties with respiratory devices, such as inhalators.

\section{Discussion}

According to our results, almost half of the polymedicated elderlies were nonadherent. In our study, nonadherence was attributed to forgetfulness, difficulties in managing medication, concerns with side effects, the price of medication, doubt about the need for the medication and the lack of trust for some medicines, showing that elderly's behaviors, beliefs, and attitudes have an impact on medication adherence.

Adherence to medication is fundamental to achieve clinical outcomes and ensure the improvement of the health being of elderly. It is well known that medication adherence is influenced by several external factors, namely psychological status of the patient and by the patient community [14]; however, there is a lack of studies regarding how the opinion and daily management of medicines by elderly people influence medication adherence.

Nonadherence to medication leads to a lack of treatment effectiveness, increased hospital admissions, healthcare expenditures, and ultimately can lead to an overtreatment of a disease [22,23]. Due to the presence of multiple comorbidities that require multiple therapies, and, consequently polypharmacy, elderlies are more prone to compliance problems and nonadherence than younger $[8,14]$. In our study, a positive correlation between the adherence levels and age was found. Despite that, according to literature, age is not a predicative factor of nonadherence to medication $[24,25]$; in fact, the elderly may choose, intentionally not take medication by several reasons, namely because they don't like medicines or to avoid adverse side effects [25]. The analysis of the medication profile of the participants revealed that drugs belonging to the ATC groups "Alimentary tract and metabolism", "Cardiovascular system", and "Nervous system" were the most prescribed drugs. These groups of drugs are frequently associated to an increased prevalence of suffering from drug-related problems [26-28].

According with Morris and Schulz [29], nonadherence to medication occurs due to the influence of friendship and family on the clinical status of the patient and can range from $40 \%$ to $75 \%$ in the elderly [30,31]. Literature reviews pointed out that, in developed countries, adherence to medication averages 50\% [32-34] and approximately half of the disease is intentional.

Adherence to medication can also be influenced by factors such as the ability to read and understand medication instructions [35,36]. In our study, despite the fact that $23.5 \%$ of the population 
does not have a grade primary school and almost $60 \%$ had only an elementary school, no correlation was observed between adherence and scholar literacy [37].

The income (receiving less than 439 EUR) has been found to be a risk factor into nonadherence. Higher income may promote higher adherence values. This is an important result considering the fact that $58.8 \%$ of our sample receives less than 439 EUR. Related to this, it is well known that poor medication adherence increases health care costs both for the National Health Service and for the elderly, worsening the income's problem [38].

Moreover, considering that income and education are so strongly correlated [39], it is not wrong to assume that the level of education might as well influence the adherence levels.

Some studies suggested that gender, personality, and cultural factors could also influence adherence [40]. In our study, the marital status and living alone did not had any correlation with adherence, which is in accordance with other studies [32,39,40].

Given that $74.6 \%$ of the participants did not know the name of their medicines, and some participants admitted that had difficulties in managing medicines, the use of strategies to the correct management of medicines and to improvement of adherence is crucial [41]. In fact, almost $40 \%$ of participants admitted that use a medication box and a huge percentage of participants admitted that put the medicines according with its daily life, e.g., put the pills in different bags/places according with the schedule that the medicines must be taken and at the beginning of the meal put the medicines on the table.

This study reinforces other research suggesting that nonadherence can be intentional or non-intentional. Non-intentional nonadherence is caused by forgetfulness, poor understanding of how or when to use medication, and this type of nonadherence can be avoided by daily routine strategies. Factors such as the lack of ability to recognize medicines and erroneous beliefs may increase nonadherence [7]. To improve medication adherence, it is essential to develop patient-centered strategies, namely physicians must understand why patients use medication incorrectly before prescribing medicines. Moreover, healthcare professionals should address patient beliefs and other factors such the fear of medicines.

Although it fills a gap in the literature by addressing daily management of medicines by elderly and adherence-related factors, this study had some limitations. The questionnaire was applied by different interviewers; however, in order to ensure the trustworthiness of the questionnaire, the questionnaire was developed after a qualitative study, a pretest was done, and the interviewers received training and a manual of applicability. Even though the sample was not randomized, the information obtained in this study is relevant and very useful to the field.

Within the MedElderly project, with the information obtained in this cross-sectional study, an intervention to improve medicines' use consisting of educational sessions and educational materials (posters and flyers) was designed addressing the major DRPs identified in the targeted population. Educational material is delivered in community pharmacies and public primary health care centers. For improving the management of medication adherence, the material includes colorful pictograms to be placed by the pharmacist in the medicine boxes.

\section{Conclusions}

Forgetfulness, difficulties in managing medication, concerns with side effects, and the price of medication were found to be significant medication management and adherence-related factors. Patients who had difficulties managing medicines, common forgetfulness, concerns with side effects, doubt of the need for the medication, considered prices expensive, and lack of trust for some medicines had a higher risk of being nonadherent. This study provides relevant information concerning the daily medication management that can be useful to develop educational strategies to promote health literacy and improve medication management and self-care for polymedicated home-dwelling elderly. 
A.F., M.T.H. and F.R.; Project administration, F.R.; Supervision, F.R.; Writing—original draft, D.G.; Writing一review and editing, A.I.P., A.F., M.T.H. and F.R. All authors have read and agreed to the published version of the manuscript.

Funding: This work was supported by project MedElderly [SAICT-POL/23585/2016], co-funded by Portuguese Foundation for Science and Technology (Fundação para a Ciência e Tecnologia-FCT/MCTES), Portugal 2020 and Centro 2020 and FEDER grants (CENTRO-01-0145-FEDER-023585).

Acknowledgments: The authors would like to thank all the interviewer students and their internship supervisors, who collaborated in the application of the questionnaire and to all the older patients that agreed to participate in the study

Conflicts of Interest: The authors declare no conflict of interest.

\section{References}

1. Ageing|United Nations. Available online: https://www.un.org/en/sections/issues-depth/ageing/ (accessed on 12 November 2019).

2. Divo, M.J.; Martinez, C.H.; Mannino, D.M. Ageing and the epidemiology of multimorbidity. Eur. Respir. J. 2014, 44, 1055-1068. [CrossRef]

3. Hao, L.J.; Omar, M.S.; Tohit, N. Polypharmacy and Willingness to Deprescribe Among Elderly with Chronic Diseases. Int. J. Gerontol. 2018, 12, 340-343. [CrossRef]

4. Sönnichsen, A.; Trampisch, U.; Rieckert, A.; Piccoliori, G.; Vögele, A.; Flamm, M.; Johansson, T.; Esmail, A.; Reeves, D.; Löffler, C.; et al. Polypharmacy in chronic diseases-Reduction of Inappropriate Medication and Adverse drug events in older populations by electronic Decision Support (PRIMA-eDS): Study protocol for a randomized controlled trial. Trials 2016, 17, 57. [CrossRef] [PubMed]

5. Morin, L.; Johnell, K.; Laroche, M.L.; Fastbom, J.; Wastesson, J.W. The epidemiology of polypharmacy in older adults: Register-based prospective cohort study. Clin. Epidemiol. 2018, 10, 289-298. [CrossRef] [PubMed]

6. Varghese, D.; Haseer Koya, H. Polypharmacy, StatPearls. 2019. Available online: https://www.ncbi.nlm.nih.g ov/books/NBK532953/ (accessed on 12 November 2019).

7. Bushardt, R.L.; Massey, E.B.; Simpson, T.W.; Ariail, J.C.; Simpson, K.N. Polypharmacy: Misleading, but manageable. Clin. Interv. Aging 2008, 3, 383-389. [CrossRef]

8. Von Buedingen, F.; Hammer, M.S.; Meid, A.D.; Müller, W.E.; Gerlach, F.M.; Muth, C. Changes in prescribed medicines in older patients with multimorbidity and polypharmacy in general practice. BMC Fam. Pract. 2018, 19, 131. [CrossRef]

9. Kaufmann, C.P.; Stämpfli, D.; Hersberger, K.E.; Lampert, M.L. Determination of risk factors for drug-related problems: A multidisciplinary triangulation process. BMJ Open 2015, 5, e006376. [CrossRef]

10. Ahmad, A.; Mast, M.R.; Nijpels, G.; Elders, P.J.M.; Dekker, J.M.; Hugtenburg, J.G. Identification of drug-related problems of elderly patients discharged from hospital. Patient Prefer. Adherence 2014, 8, 155-165. [CrossRef]

11. Nickel, C.H.; Ruedinger, J.M.; Messmer, A.S.; Maile, S.; Peng, A.; Bodmer, M.; Kraehenbuehl, S.; Bingisser, R. Drug-Related emergency department visits by elderly patients presenting with non-specific complaints. Scand. J. Trauma Resusc. Emerg. Med. 2013, 21, 15. [CrossRef]

12. Hilmer, S.N.; Gnjidic, D. The effects of polypharmacy in older adults. Clin. Pharmacol. Ther. 2009, 85, 86-88. [CrossRef]

13. Ernst, F.R.; Grizzle, A. Drug-Related Morbidity and Mortality: Updating the Cost-of-Illness Model. J. Am. Pharm. Assoc. 2001, 41, 192-199. [CrossRef]

14. Martin, L.R.; Feig, C.; Maksoudian, C.R.; Wysong, K.; Faasse, K. A perspective on nonadherence to drug therapy: Psychological barriers and strategies to overcome nonadherence. Patient Prefer. Adherence 2018, 12, 1527-1535. [CrossRef] [PubMed]

15. Countries with the Largest Aging Population in the World-WorldAtlas. Available online: https://www. worldatlas.com/articles/countries-with-the-largest-aging-population-in-the-world.html (accessed on 12 November 2019).

16. PORDATA—Índice de Envelhecimento. Available online: https://www.pordata.pt/Municipios/Índice+de+ envelhecimento-458 (accessed on 12 November 2019).

17. Roque, F.; Placido, A.I.; Lima, F.; Herdeiro, M.T. What Think Older Patients About Their Medicines? Drug Saf. 2018, 41, 1242. [CrossRef] 
18. Roque, F.; Plácido, A.I.; Lima, F.; Herdeiro, M.T. Exploring Health Professionals Perceptions About Drug Related Problems in Older Patients. Drug Saf. 2018, 41, 1237-1238. [CrossRef]

19. Roque, F.; Plácido, A.I.; Simões, J.L.; Amaral, O.; Plácido, C.; Fonseca, A.M.; Lima, F.; Herdeiro, M.T. A questionnaire design to assess patient-related causes of drug related problems in older patients. Gac. Sanit. 2019, 33, 253-254. Available online: http://www.gacetasanitaria.org/es-vol-33-num-sc-sumario-X0213911119 X00C10-portada (accessed on 12 November 2019).

20. Barata Delgado, A.; Luísa Lima, M. Contributo para a validação concorrente de uma medida de adesão aos tratamentos. Psicol. Saúde Doenças 2001, 2, 81-100. Available online: http://www.scielo.mec.pt/scielo.php?scr ipt=sci_arttext\&pid=S1645-00862001000200006 (accessed on 12 November 2019).

21. WHO Collaborating Centre for Drug Statistics Methodology-ATC/DDD. Available online: https://www.wh occ.no/atc_ddd_index/ (accessed on 12 November 2019).

22. Toh, M.R.; Teo, V.; Kwan, Y.H.; Raaj, S.; Tan, S.Y.D.; Tan, J.Z.Y. Association between number of doses per day, number of medications and patient's non-compliance, and frequency of readmissions in a multi-ethnic Asian population. Prev. Med. Rep. 2014, 1, 43-47. [CrossRef]

23. Chisholm-Burns, M.A.; Spivey, C.A. The cost of medication nonadherence: Consequences we cannot afford to accept. J. Am. Pharm. Assoc. 2012, 52, 823-826. [CrossRef]

24. Yap, A.F.; Thirumoorthy, T.; Kwan, Y.H. Medication adherence in the elderly. J. Clin. Gerontol. Geriatr. 2016, 7, 64-67. [CrossRef]

25. Hughes, C.M. Medication non-adherence in the elderly: How big is the problem? Drugs Aging 2004, 21, 793-811. [CrossRef]

26. Peterson, C.; Gustafsson, M. Characterisation of Drug-Related Problems and Associated Factors at a Clinical Pharmacist Service-Naïve Hospital in Northern Sweden. Drugs Real World Outcomes 2017, 4, 97-107. [CrossRef] [PubMed]

27. Blix, H.S.; Viktil, K.K.; Reikvam, Å.; Moger, T.A.; Hjemaas, B.J.; Pretsch, P.; Vraalsen, T.F.; Walseth, E.K. The majority of hospitalised patients have drug-related problems: Results from a prospective study in general hospitals. Eur. J. Clin. Pharmacol. 2004, 60, 651-658. [CrossRef] [PubMed]

28. Brulhart, M.I.; Wermeille, J.P. Multidisciplinary medication review: Evaluation of a pharmaceutical care model for nursing homes. Int. J. Clin. Pharm. 2011, 33, 549-557. [CrossRef] [PubMed]

29. Morris, L.S.; Schulz, R.M. Patient compliance-An overview. J. Clin. Pharm. Ther. 1992, 17, $283-295$. [CrossRef] [PubMed]

30. Salzman, C. Medication compliance in the elderly. J. Clin. Psychiatry 1995, 1, 18-23.

31. Cutler, R.L.; Fernandez-Llimos, F.; Frommer, M.; Benrimoj, C.; Garcia-Cardenas, V. Economic impact of medication non-adherence by disease groups: A systematic review. BMJ Open 2018, 8, e016982. [CrossRef]

32. World Health Organization. Adherence to Long-Term Therapies: Evidence for Action/Edited by Eduardo Sabaté; World Health Organization: Geneva, Switzerland, 2003; ISBN 9241545992.

33. Jimmy, B.; Jose, J. Patient medication adherence: Measures in daily practice. Oman Med. J. 2011, 26, 155-159. [CrossRef]

34. Carter, S.; Taylor, D. A Question of Choice-Compliance in Medicine Taking: From Compliande to Concordance, 3rd ed.; Medicines Partnership: London, UK, 2005.

35. Pandey, A.; Suskin, N.; Patel, T.; Choudhry, N. Lower educational levels may be an important determinant of adherence to evidenced-based therapies in post-mi patients. J. Am. Coll. Cardiol. 2017, 69, 1847. [CrossRef]

36. Uchmanowicz, B.; Chudiak, A.; Uchmanowicz, I.; Rosińczuk, J.; Froelicher, E.S. Factors influencing adherence to treatment in older adults with hypertension. Clin. Interv. Aging 2018, 13, 2425-2441. [CrossRef]

37. Praska, J.L.; Kripalani, S.; Seright, A.L.; Jacobson, T.A. Identifying and assisting low-literacy patients with medication use: A survey of community pharmacies. Ann. Pharmacother. 2005, 39, 1441-1445. [CrossRef]

38. Kalogianni, A. Factors affect in patient adherence to medication regimen. Health Sci. J. 2011, 5, 157-158.

39. Earnings Statistics-Statistics Explained. Available online: https://ec.europa.eu/eurostat/statistics-explained/i ndex.php/Earnings_statistics\#Higher_level_of_education_yields_higher_earnings (accessed on 12 November 2019).

40. Ward, A.; Morgan, W. Adherence patterns of health in men and women enrolled in an adult exercise program. J. Cardiac. Rehabil. 1984, 4, 143-152. 
41. Brooks, T.L.; Leventhal, H.; Wolf, M.S.; O'Conor, R.; Morillo, J.; Martynenko, M.; Wisnivesky, J.P.; Federman, A.D. Strategies Used by Older Adults with Asthma for Adherence to Inhaled Corticosteroids. J. Gen. Intern. Med. 2014, 29, 1506-1512. [CrossRef] [PubMed] 